\title{
Using Learners' Home Languages in English Classrooms: Multilingual Awareness of Teachers
}

\author{
Resham Acharya \\ reshamacharya02@gmail.com \\ Central Department of Education, T.U., Kirtipur
}

\begin{abstract}
The field of pedagogy has ever been debated and discussed issue in terms of approaches, methods, and strategies to be adopted. Especially, the use of learners' languages and cultures has recently been more critically observed. Although the proponents of traditional methods such as the direct method and audio-lingual method strongly believed that the use of learners' L1 hinders SL/FL learning,scholars such as Cummins (2007) and Garcia (2008) have indicated the supportive role of learners' home languages in EFL classrooms. Being inspired by recent works of literature, this study was carried out to analyse teachers' multilingual awareness, particularly focusing on the use of learners' home languages in English classrooms. The findings of the study showed that teachers are multilingually aware of children's home languages and advocate for using those languages in English classrooms. Particularly, considering the reasons for using such languages in English classrooms, the study indicated that children's home languages help to develop the concept and build knowledge, to promote learners' participation in learning activities, and to create spaces for minority children in terms of language.
\end{abstract}

Key words: Multilingual awareness, learners' home language, English classroom, basic level, phenomenology

\section{Introduction}

Nepal is a linguistically diverse country accommodating more than 123 languages (CBS, 2012), where English is taught and learnt as a foreign language. The use of learners' home languages in English as foreign language (EFL) classrooms has ever been a controversial issue. On the one hand, the theory and practice of established methods such as direct method and audio-lingual method discourage the use of learners' home languages in foreign language (FL) classrooms. These methods emphasize monolingual pedagogy in SL/FL and suggest that the target language ought to be the sole medium of communication, implying the prohibition of such languages would maximize the effectiveness of learning the target language (Paker \& Karaagac, 2015). In this sense, these methods impel that while teaching and learning of English, English should be the language of communication and the sole medium of instruction for providing the learners with better opportunities to get required input and develop greater proficiency in English. However, some works of literature have also shown that educating children in dominant language in EFL 
contexts deprives them from their rights to education. For example, Kandel's (2013) study, taking the case of Nepal, reported that only use of English in EFL classrooms has excluded linguistically minoritized children from their rights to education.

On the other hand, some other works of literature have emphasized the judicial use of learners' home language(s) in English classroom. For example, Larsen-Freeman (2000) states "The native language [here the home language] of the students is used in the classroom in order to enhance the security of the students, to provide a bridge from the familiar to the unfamiliar, and to make the meanings of the target language words clear" (pp. 101-102). Scholars like Cummins (2007), Garcia (2008), Felm (2017), and Cenoz, Gorter and May (2017) have also indicated more positive roles of learners' home languages than negative ones. These languages are argued to scaffold in learning dominant language [i.e. learning English in Nepal] (Garcia, 2008) with the belief that learners' first language and second/foreign languages are interdependent in language learning (Cummins, 1979). This infers "new understandings are constructed on a foundation of existing understandings and experiences" (Cummins, 2007, p. 232). Such languages, in English classrooms, recognize a child's mother tongue, culture and context (Felm, 2017) and identify learners' social, political and economic pressures (Garcia, 2008) that benefit the learners in learning English.

To be specific, the use of learners' home languages in classrooms is reported to help them understand the concept better as they receive authentic language data (Wright, 2002) and improve their learning outcomes (UNESCO, 2014) as it promotes interaction between learners and teachers by means of better communications with better understandings. UNESCO (ibid) further reports that the use of learners' home languages facilitatesthe learning of both academic subjects and second language as they can have better opportunities to concentrate on the subject matter at school instead of struggling to understand the language of instruction in English. Therefore, teachers, in EFL classrooms, should draw learners' attention to similarities and differences between their languages and reinforce effective learning strategies in a coordinated way across languages especially by engaging prior understandings, integrating factual knowledge with conceptual framework, and taking active control over the learning process through metacognitive strategies (Cummins, 2007).

Moreover, learners' home languages in EFL classrooms provide a sense of security and validates their lived experiences, allowing them to express themselves (Schweers, 1999), and take risks with English. Studies such as Cook (2001) and Greggio and Gil (2007) have also reported that learners' L1 in English classes is used for various purposes such as explaining the grammar, giving instructions, helping students/checking them, correcting the activities. Next, L1 is also used for motivating purpose and helping students cope with some problematic situations (Duff and Polio, 1990). Besides, L1 helps maintain discipline, build rapport and reduce social distance with students (Jingxia, 2009). Teachers often switch languages between the foreign language and the home language in the classrooms and that help to check understanding, to clarify and to socialize (Moghadam et al., 2012). Moreover, it is used to give the meaning of unknown vocabularies (Senel, 2010) which is found economical and is a direct route to a word's meaning 
(Thornbury, 1999). Furthermore, L1 is also used to arouse students' interest towards the lesson (Yildirim and Mersinligil, 2000).

Regarding the use of learners' home language(s) in English classroom, the literature discussed above have shown two opposite arguments. Scholar such as Paker and Karaagac, (2015) has argued for complete ban of learners' home language in English classrooms claiming that such language(s) may play the role negatively. In contrast, some other scholars such as Cummins (1979, 2007), Schweers, (1999), Cook (2001) and Garcia (2008) have shown the positive roles of L1. EFL teachers in Nepal are also, whether knowingly or unknowingly, found to use Nepali and other local languages in English classrooms. Hence, considering Garcia's (2008) theory of multilingual awareness, this study aimed to explore the reasons of using learners' home languages in English classrooms from the perspectives of English language teachers teaching at basic level in Nepalese community schools.

\section{Theoretical Framework}

Informed by perspective that the use of learners' home languages in English class might provide greater opportunities in learning,this study takes multilingual awareness as a theoretical base. Language awareness (LA), in general, is "explicit knowledge about language, and conscious perception and sensitivity in language learning, language teaching and language use" (Cenoz, Gorter and May, 2017, p. ix). It is a person's sensitivity to a conscious awareness of the nature of language and its role in human life (Donmall, 1985 cited in Finkbeiner \& White, 2017). LA, also known as knowledge about language (KAL) in teaching (Cots, 2008), critical language awareness (Fairclough 1990), or multilingual language awareness (Garcia, 2008), is used to encompass understandings about language, its teaching and its learning (Wright, 2002) based on the roles described by Edge (1988). The first is knowledge of language proficiency, which includes ability to use language appropriately in many situations(i.e. awareness of social and pragmatic norms). The second is the knowledge about language, which includes forms and functions of systems such as grammar, phonology, vocabulary.The third is pedagogical practice, which includes creating language learning opportunities and classroom interaction. Typically, this study utilizes the knowledge of and about language for creating language learning opportunities.

However, this study does not take language awareness as "long-held normative ascendency of monolingualism" (Cenoz, Gorter\& May, 2017, p.vi) in relation to language acquisition, use, teaching and learning; but as the one that is relevant to the twenty first century's essence including the norms of multilingualism and diversity from the perspective of "multilingual turn" (May, 2014). Hence, this study makes use of multilingual awareness as theory. The multilingual awareness is the understanding of the social, political and economic struggles surrounding the use of two or more languages (Garcia, 2008) in learning another dominant language (i.e. English in Nepalese classrooms). For Shohamy (2006), it is understanding of the ways in which languages are used in undemocratic ways to exclude and discriminate minority languages. This study, typically, adopts teachers' multilingual awareness in English classrooms. The teachers' multilingual awareness, I believe, is their understandings of and about multiple languages surrounding school community and using those understandings in English classrooms to enhance learners' learning. 


\section{Methods and Procedures}

This study, rather than validating existing single meaning, has attempted to explore multiple meanings created from participants using interpretive or constructive paradigm and adopted qualitative research. Particularly, I used phenomenological study, which explains being and consciousness on the basis of the analysis of observable phenomena (Litchman, 2006) not being based on a priori knowledge independent from experience (Parodi, 2008 cited in PadillaDiaz, 2015). It emphasizes the meanings and objects based on the conscience of phenomena highlighting elements related to human perception and the intentionality of consciousness. The intentionality of consciousness refers to the search and identification of subjacent, subjective elements of consciousness which surpass the intention of understanding reality from single point of view (Padilla-Diaz, 2015). Further, as a method, it proposes the suspension or suppression of judgments and the positioning of the researcher with regard to the experiences of the studied phenomenon (Giorgi, 2009). Thus, this study, as per the essence of phenomenological research design, has attempted to draw the lived experiences of subjects upon the use of learners' home languages in English classrooms.

Believing that the teachers teaching students from diverse language background could best provide their experiences about the use of learners' home language(s) in English classroom, I first made a pilot visit to find the multilingual schools. Then, I chose two community schools using judgmental sampling procedure and two English teachers from there. Believing that basic level students are more frequently taught using their familiar language(s), I purposively chose basic level teachers.

To collect data for the study, I used in-depth qualitative interviews with the teachers. To gather the required information, I interviewed the teachers thrice. As per the nature of the study, I used qualitative approach to data analysis in general including transcribing, editing, summarizing, organizing, categorizing, deriving conclusions (Attride-Sterling, 2001). Particularly, I used thematic approach to analyse the data collected from the sampled teachers.

Despite debatable arguments behind the use of learners' home languages in English classroom; Nepalese teachers of English, whether knowingly or unknowingly, are frequently found to use such languages in English classroom. Therefore, this study, in general, aims to analyse teachers' multilingual awareness and the reasons for using and allowing the use of learners' home languages in English classes.

\section{Results and Discussions}

The general purpose of this study was to analyse multilingual awareness of teachers in Nepalese community schools and it especifically focused on the use of learners' home languages with limitation to reasons for using such languages in English classrooms. The major reasons for using learners' home languages in English classroom, as explored in the study, have been presented under the following three themes; 


\section{Concept development and knowledge construction}

The teachers shared that the use of learners' home or familiar languages in English classrooms helped learners in understanding new concepts although they were aware of the common belief of people that using L1 in L2 classrooms hinders L2 learning. For example, one of the participants said:

... because our school has followed EMI policy ... I do not generally use Nepali and other local languages ... but when the students feel difficult to understand the concepts such as culture related concept like 'Maha Puja' ... I describe them through Newari language to Newar children ... and ... through Nepali to Nepali speaking children. (Source: Interview with T2)

The data show that teachers often use learners' home or familiar languages in English classrooms in case they have to present culture related terms to their students. They experienced that their students often felt difficult to understand others' culture and in that case if they (Teachers) use local languages, their students do not have to struggle for understanding the concept. The teachers also added that the use of such languages also helped their learners acquire knowledge with less struggle as one of participant teachers said;

The use of learners' familiar languages may be hindrance for language development in second/foreign language ... but I find my students feel easy in understanding if I present the new concept ... so I feel it has helped them in acquiring knowledge... (Source: Interview with T1)

The data show that the teachers give importance to developing knowledge to learning language itself. The teachers argued that although the use of learners' mother tongue is claimed to hinder second language learning, they experienced positive roles using learners' home languages in English classrooms. They argued that using and allowing the use of learners' home languages supports the acquisition of knowledge by transferring knowledge in L1 to learning L2. This situation is similar to what Cummins' (2007) argument that "new understandings are constructed on a foundation of existing understandings and experiences" (p. 232) with better conceptual development through authentic language data (Wright, 2002). The data also show that learners learn the concepts in L2 by analyzing similar concepts in L1, which Cots (2008) calls a metalinguistic awareness. The data further show that the learners bring their cultural significance in learning English as Garcia (2008) and Felm (2017) advocate that learners' social, cultural and political contexts are supportive for developing knowledge in dominant language classroom. Hence, on the basis of teachers' responses, it is argued that learners' home languages are used for concept development and knowledge construction.

\section{Promoting learners' involvement in learning}

Increasing learners' involvement in second or foreign language classroom is really challenging for every teacher due to lack of sufficient target language competence among the learners. In such situation, the participant teachers experienced that the use of learners' home or familiar 
languages play significant role to engage learners in teaching and learning process. For example, one of the teachers said:

... why to become so smart among the learners by only speaking English ... nor should I compel them use English only ... If I do so, neither they understand what I ask nor can they respond my questions ... They only look down ... So, I let them use Nepali and their familiar language(s) ... At least, they participate in learning activities ... and express clearly what they have known ... and put their arguments easily and clearly (Source: Interview with T1)

The quotation shows that use of only English in English classrooms does not fully engage the students in learning process. The teachers believed that the students neither understand the things discussed and the questions asked nor do they answer any questions and engage in learning activities. In other words, obligation in using English in the classrooms does not provide the students with appropriate environment to participate in learning activities. However, the teachers experienced that the use of learners' home or familiar languages create more dynamic environment in which the students eagerly express the things they know and put their arguments more clearly and easily. This is the situation similar to Felm's (2017) observation that the use of familiar languages provides the learners with greater opportunities to get involved in learning activities.

The teachers, even in EMI schools as well, were found to practice multilingualism. To be specific, they used and allowed their students to use their home languages or other familiar languages. For example, a participant teacher from EMIschool said;

We have implemented EMI in school, so as an English teacher, I have to dominantly use English. But my students do not have sufficient knowledge in English so that they could understand everything I tell ... even they do not interact in classroom. However, I find them more motivated to participate in classroom interaction when I allow them to use the languages they know... (Source: Interview with T2)

The data show that the teachers teaching at EMI schools were also aware of the role of students' home languages although they needed to dominantly use English. They experienced that the students feel easy to interact in classroom in transition to English only classroom when they are allowed to use their home languages. Moreover, the students are also found to be more motivated when they are allowed to use their own languages in classroom. In this sense, learners' home languages are used also for motivating purpose in coping with problematic situations in interaction created by exclusive use of English (Duff \& Polio, 1990).

\section{Creating spaces for minority children}

English is one of the most difficult subjects among the community school students in many nonEnglish speaking countries like Nepal. The higher failure rate in English is one of the concrete evidences to prove it as a difficult subject and due to which many students are found to drop out from education. To overcome this situation, the participant teachers argued that the use of 
learners' home languages, in transition to English, can create spaces for students from nonEnglish background. For example, one of the participants said;

When our school, for the first time, implemented EMI, we used English throughout the classes. We were also motivated to implement it assuming that we could compete to private boarding schools ... We did not think of whether our students were enjoying or not. But in the exam results, most students failed ... then we surveyed upon the students and found that they were feeling difficult to tackle with English only classroom ... then we started using Nepali as well ... even in English classroom. (Source: Interview with T2)

The data show that the implementation of EMI has been found to cause students' failure in their academic achievement and grade promotion. The teachers thought that the reason behind their students' failure was not other than dominant use of English in classrooms. They claimed that the use of learners' languages such as Nepali in English classrooms has made learning English easier and also has reduced students' dropout rate. Similar response was forwarded by another participant by saying;

I think it is necessary to use English in English classroom ... however, if the students do not understand and use even a single English sentence, teachers can use any language that is familiar to students ... and I also have been doing this ... because my role is to make them acquire knowledge and ensure their right to education. (Source: Interview with T1)

The data show that the role of the teachers is to impart knowledge and make the students acquire that knowledge. For this, although teachers need to use and make their students use English in English classrooms, they often used and allowed the use of learners' home languages or any other familiar languages so that they could not be deprived of education. This shows that English has grabbed students' right to education. In this sense, the use of learners' home languages is found to ensure the right of education to the minority children (Kandel, 2013) by reducing social distance (Jingxia, 2009) and creating their spaces in dominant language environment (Garcia, 2008; Shohamy, 2006; Schweers, 1999).

\section{Conclusions and Implications}

The purpose of this study was to analyse teachers' multilingual awareness, especially focusing on the use of learners' home languages in English classrooms. The use of learners' home languages in English classroom has been a debated issue in the literature of second/foreign language pedagogy. As shown in the literature discussed earlier, the use of these languages have been taken both positively and negatively (i.e. as supportive and hindrance respectively). This study particularly took the recent literature such as Garcia (2008), Cummins (2007), Felm (2017), Cenoz, Gorter and May (2017) that emphasize the positive role of learners' languages in dominant language classroom (i.e. English in Nepalese context). The use of dominant language could be the "hegemonic" (Phillipson, 1992) as it deprives the learners from minority languages [all the languages other than English] from learning. Nepalese teachers were also found to believe that 
use of English only in the classroom grab learners' right to education and favour multilingual practices even in dominant language classroom. Particularly, in exploring the reasons for practicing multilingualism (i.e. the use of learners' home languages), the study shows mainly three arguments. First, the use of learners' home languages was considered to be supportive for concept development and knowledge construction in dominant language classrooms by transferring those from learners' existing knowledge and experiences. Second, these languages were used as motivational means for involving the learners in classroom interaction and other learning activities. Third, in teachers' view, these languages helped the learners identify their self in dominant language classroom so that they did not feel being discriminated in classroom. Hence, Nepalese teachers teaching English to basic level students prefered the use of local languages to create more learning opportunities to the learners of English. Therefore, on the basis of the findings of the study, I would like to suggest English language teachers teaching in any non-English speaking context to use and let the learners use their languages to enhance their learning and create their spaces in dominant language so that they could not be deprived of their right to education.

\section{References}

Attride-Sterling, J. (2001). Thematic networks: An analytic tool for qualitative research. Qualitative Research, 1(3), 385-405.

Cenoz, J., Gorter, D. \& May, S. (2017). Language awareness and multilingualism. Switzerland: Springer International Publishing Switzerland.

Central Bureau of Statistics (2012).National population and housing Census 2011. Kathmandu: National Planning Commission Secretariat.

Cook, V. (2001). Using first language in the classroom. The Canadian Modern Language Review, $57(3), 402-423$.

Cots, J.M. (2008).Knowledge about language in the mother tongue and foreign language curricula.In J. Cenoz\& N. H. Hornberger (Eds.), Encyclopedia of language and education (Knowledge about language 2nd ed., 6, 15-30). New York: Springer.

Cummins, J. (1979). Linguistic interdependence and the educational development of bilingual children.Review of Educational Research, 49, 222-251.

Cummins, J. (2007). Rethinking monolingual strategies in multilingual classrooms.Canadian Journal of Applied Linguistics, 10(2), 221-240.

Duff, P. A., \& Polio, C. G. (1990). How much foreign language is there in the foreign language classroom? The Modern Language Journal, 74 (2), 154-166.

Edge, J. (1988).Applying linguistics in English language teacher training for speakers of other languages.ELT Journal 42(1), 9-13.

Felm (2017).Mother tongue based multilingual education among linguistic minorities. Helsinki. 
Finkbeiner, C \& White, J. (2017). Language awareness and multilingualism: A historical overview. In J. Cenoz, D. Gorter and S. May (Eds.), Language Awareness and Multilingualism, 3rd edition. Switzerland: Springer International.

Garcia, O. (2008). Multilingual language awareness and teacher education. In J. Cenoz\& N. Hornberger (eds.) Encyclopedia of language and Education, $2^{\text {nd }}$ edition, vol.6 : Knowledge about Language, Berlin, Springer, 385-400.

Giorgi, A. (2009). A descriptive phenomenological method in psychology: A modified Husserlian approach. Pittsburg, PA: Duquesne University Press.

Greggio, S., \& Gil, G. (2007). Teacher's and learners' use of code switching in the English as a foreign language classroom: a qualitative study. Linguagem\&Ensino, 10, (2), 371-393.

Jingxia, L. (2009). Switching to L1 in the EFL classroom-the perspective of adaptation.The Open Applied Linguistics Journal, 2, 45-49.

Kadel, S. (2013).Language choice and use in multilingual contexts of Nepal: An ethnographic study. (Doctoral dissertation, Jawaharlal Nehru University. Retrieved from file://C:/ Users/lbcc/Desktop/Downloads/Sadananda_PHD_Thesis.pdf

Kumar, R. (2011). Research methodology: A step-by-step guide for beginners. London: SAGE Publications Ltd.

Larsen-Freeman. D. (2000).Techniques and principles in language teaching. Oxford: Oxford University Press.

Litchman, M. (2006).Qualitative research in education: A user's guide. Thousand Oaks, CA: Sage.

May, S. (2014). The multilingual turn: Implications for SLA, TESOL and teacher education. New York and London: Routledge.

Moghadam, S. H., Samad, A. A., \& Shahraki, E. R. (2012).Code switching as a medium of instruction in an EFL classroom. Theory and Practice in Language Studies, 2 (11), 2219-2225.

Padilla-Diaz, M. (2015). Phenomenology in educational qualitative research: Philosophy as science or philosophical science? International Journal of Educational Excellence, l(2), 101-110.

Paker, T. \& Karaagac, O. (2015). The use and functions of mother tongue in EFL classes. Procedia-Social and Behavioral Sciences, 199, 111-119.

Phillipson, R. (1992). Linguistic imperialism. Oxford: OUP.

Schweers, C.W. Jr. (1999). Using L1 in the L2 classroom. English Teaching Forum, 37(2), 6-9.

Senel, M. (2010). Should foreign language teaching be supported by mother tongue? Journal of Language and Linguistic Studies, 6(1), 110-120. 
Shohamy, E. (2006). Imagined multilingual schools: How come we don't deliver? In O. Garcia, T. Skutnabb-Kangas, and M. Torres-Guzman (eds.), Imaging Multilingual Schools: Language in Education and Globalization, Multilingual Matters, Clevedon.

Thornbury, S. (2005).How to teach speaking. Malaysia: Pearson education Limited.

UNESCO (2014).Mother tongue based multilingual education. Indonesia: ACDP Indonesia.

Wright, T, (2002). Doing language awareness: Issues for language study in language teacher education. In H. Trappes-Lomax \& G. Ferguson (eds.), Language in Language Teacher Education, John Benjamins, Amsterdam.

Yildirim, R., \&Mersinligil, G. (2000). Use of mother tongue in ELT classes: When and why? Çukurova University Journal of Social Sciences Institute, 6(6), 131-142. 